\title{
Sex Differences in Young Adults' Attraction to Opposite-Sex Friends: Natural Sampling versus Mental Concepts
}

\author{
April Bleske-Rechek $^{1}$ - Whitney E. Joseph ${ }^{1} \cdot$ Heather Williquette ${ }^{1} \cdot$ Bryan Donovan $^{1}$
}

Published online: 11 May 2016

(C) Springer International Publishing 2016

\begin{abstract}
When young adults are asked to either think of an opposite-sex friend or bring an opposite-sex friend to the lab, men report much more attraction to their friend than women do (Bleske-Rechek et al. Journal of Social and Personal Relationships, 29: 569-596, 2012; Kaplan and Keys Journal of Social and Personal Relationships, 14: 191-206, 1997). In two studies, we utilized a naturalistic sampling strategy to obtain our friendship dyads. We approached and surveyed male-female dyads who were lounging at a university student center and found that the mean difference between male and female friends' attraction to one another was weak and statistically unreliable. We speculated that the opposite-sex friends that men and women find themselves with in their everyday life might be different from the opposite-sex friends who come to mind when asked by researchers to think of their friends. Men's and women's mating adaptations, which differ particularly in attention to attractiveness and proclivity toward shortterm sex, might be reflected in how men and women conceptualize opposite-sex friends; hence, previous studies may have documented a stronger sex difference in attraction because men and women in those samples had different types of people in mind when they thought about opposite-sex friends. To test that possibility, we asked young adults to "think of an opposite-sex friend" and then choose descriptors for that person. Men less often than women characterized the person as "a friend" and more often than women characterized the person as someone they were "attracted to." We conclude that men's
\end{abstract}

April Bleske-Rechek

bleskeal@uwec.edu

1 Psychology Department, University of Wisconsin-Eau Claire, 105 Garfield Avenue, Eau Claire, WI 54702, USA and women's everyday experiences with opposite-sex friends differ from their mental conceptions of opposite-sex friends.

Keywords Opposite-sex friends · Friendship · Attraction · Naturalistic sampling

Among young adults in modern society, friendships with members of the opposite sex are common (Monsour 2002) and highly valued (Baumgarte and Nelson 2009). One of the unique challenges for opposite-sex friends is convincing others that the relationship is platonic (O'Meara 1989; Schoonover and McEwan 2014; Werking 1997). Perhaps that challenge is rooted in a kernel of truth, because approximately half of romantically involved couples report that they were friends prior to becoming romantically involved (Hunt et al. 2015), and young men and women in various contexts report experiencing some form of attraction to, or sexual involvement with, their opposite-sex friends (Afifi and Faulkner 2000; Kaplan and Keys 1997; Reeder 2000; Swain 1992).

Evolutionary researchers have proposed that opposite-sex friendships might trigger men's and women's mating strategies (Bleske and Buss 2000; Bleske-Rechek et al. 2012). For example, men's stronger attention to physical attractiveness (Buss 1989) and short-term mating orientation (Buss and Schmitt 1993), relative to women's, should manifest in their experiences with opposite-sex friendships. Indeed, one of the most consistent findings on attraction in young adults' opposite-sex friendships is that men report more attraction to their opposite-sex friends than women do (Bleske-Rechek and Buss 2001; Kaplan and Keys 1997; Bleske-Rechek et al. 2012). For example, Kaplan and Keys (1997) had US undergraduates tell them about a close cross-sex friend of theirs; when the participants reported how physically attractive they thought their closest cross-sex friend was, how much they 
would enjoy having sex with their friend, and how often they touched their friend, men's ratings were substantially higher than women's (mean difference of 3.5 on a 21-point scale; $d=0.72$ ). When Bleske-Rechek and Buss (2001) asked a sample of US undergraduates to think about their "closest, most important opposite-sex friend who is not a long-term romantic partner," men rated their friend as more sexually attractive than women did (mean difference of 1.5 on a seven-point scale; $d=0.45$ ) and reported more frequent desire to have sex with their friend than women did (mean difference of 1.5 on a seven-point scale; $d=0.41$ ). In another study, Bleske-Rechek et al. (2012) asked young men and women to bring with them to the lab a "friend of the opposite sex who was neither from class nor a family member or romantic partner." The researchers assessed sexual attraction and physical attraction (alpha $=.93)$ and found that in these dyads, men reported more attraction to their friend than women did (mean difference of 1.0 on a nine-point scale; $d=0.66$ ). In the aggregate, these findings suggest a moderate-sized sex difference in attraction to opposite-sex friends, even those presumably selected according to platonic specifications.

In study 1 , we were interested in replicating the difference between young men's and young women's attraction to their opposite-sex friends. We approached opposite-sex dyads who were passing time at a university student union and, upon their consent, surveyed each partner independently about their perceptions of one another and their relationship.

\section{Study 1}

\section{Method}

During the 2013-2014 academic year, a male-female pair of researchers approached young adult male-female dyads who were eating or sitting together at a university student union during the lunch hour. The researchers invited them to participate in a brief "study of dyads." Refusal to participate was uncommon (in fact, several students approached the researchers asking what they were doing and proceeded to participate); however, a few dyads declined because they were heading to class or getting ready to get in line for food. Upon consent, partners were physically separated by the researchers and stood with a clipboard as they completed the questionnaire. In addition to ratings of their own and their partner's attractiveness and personality that were included for purposes outside of the current analysis, participants used a seven-point scale to report the degree to which they were physically attracted to their partner (not at all to moderately to extremely).

At the end of the one-page questionnaire, participants independently reported their dyad relationship status as "We are just friends," "We are in a romantic relationship," or "Other."
We did not include an additional question pertaining to each individual's relationship status (as single or involved). We omitted two dyads that included one participant of homosexual orientation, two who were cousins, two who provided discrepant reports of their relationship status (i.e., friends versus romantic partners), and two that included one member who said it was too early to tell what their relationship status was. The final sample included 40 pairs of opposite-sex friends, with a mean friendship duration of 99.24 \pm 25.61 weeks. Mean ages were $19.70 \pm 1.47$ for men and $19.37 \pm 1.28$ for women. The dataset also included ratings from 37 dating couples, but we focus here on just the responses from friendship dyads.

\section{Results and Discussion}

Men's and women's mean level of physical attraction to the opposite-sex friend they were with when we surveyed them was low to moderate. As displayed in Fig. 1, a within-sample $t$ test revealed that men $(M=3.93, \mathrm{SD}=1.53)$ and women $(M=3.35, \mathrm{SD}=1.76)$ did not differ statistically $[t(39)=1.64$, $p=.109]$ in their reported levels of attraction $\left(M_{\mathrm{d}}=0.58[95 \%\right.$ $\mathrm{CI}-0.13,1.28]$ ), and the magnitude of the sex difference was weak, $d=0.26$. Both men and women varied widely in their reported attraction: $8 \%$ of men and $23 \%$ of women reported they were "not at all" attracted to their friend, and $60 \%$ of men and $50 \%$ of women reported at least moderate attraction.

In short, we failed to replicate the significant sex difference documented in previous studies (Bleske-Rechek and Buss 2001; Bleske-Rechek et al. 2012; Kaplan and Keys 1997). The sex difference we observed was small in magnitude, rather than moderate to strong, and not statistically significant. We speculated that our sampling method was an explanatory factor. That is, we had not asked people to tell us about a friend of theirs but instead approached friends in their "natural habitat." Are the members of the opposite sex with whom young adults pass their time in an everyday context different from the members of the opposite sex that they visualize when researchers ask about their friends? Before pursuing that possibility further, we first attempted to replicate the pattern we had just observed.

\section{Study 2}

\section{Method}

Study 2 took place during the subsequent academic year; it was embedded in a broader study of similarity between friends and romantic partners in moral attitudes and values. As in study 1 , dyads were approached and, upon consent, the partners independently completed a brief questionnaire. Toward the end of the questionnaire, participants used a seven-point 
Fig. 1 Men's and women's mean level of physical attraction to the opposite-sex friend they were with when they were approached

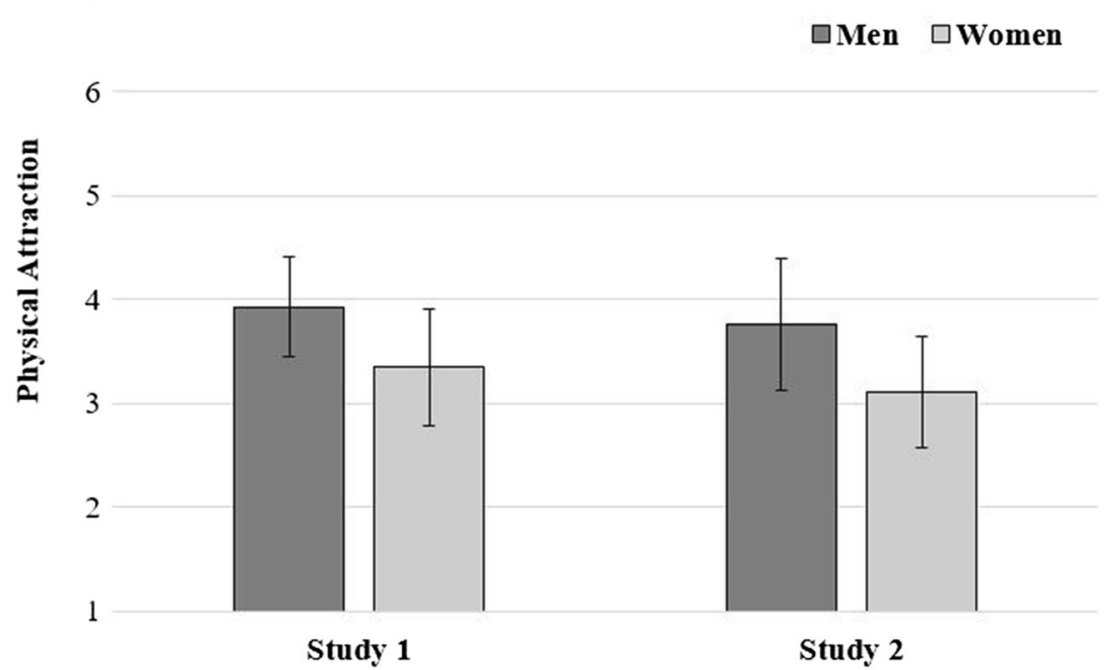

scale to report the degree to which they were physically attracted to their partner (not at all to moderately to extremely). Then, participants selected the dyad's relationship status from several options: acquaintance, casual friend, close friend, romantic partner, roommate, sibling/relative, and other. There were three pairs who differed in their perception of their friendship as close versus casual, but there were no pairs with discrepant views on their relationship status as friends versus romantically involved. As in study 1 , the questionnaire did not include an additional item pertaining to each individual's relationship status (as single or involved). Refusal was uncommon, with a total of 139 dyads involved. For purposes of the current research question, however, we report only on the opposite-sex friends who participated. The sample included 38 pairs of opposite-sex friends (mean friendship duration of $50.87 \pm 9.32$ weeks), with men's mean age at 20.50 \pm 1.80 years and women's mean age at $19.84 \pm 1.35$ years.

\section{Results and Discussion}

Study 2 replicated the pattern from study 1 . As displayed in Fig. 1, young men $(M=3.76, \mathrm{SD}=1.95)$ and women $(M=3.11, \mathrm{SD}=1.69)$ did not differ statistically $[t(37)=1.83$, $p=.076]$ in their mean level of physical attraction to one another $\left(M_{\mathrm{d}}=0.66[95 \% \mathrm{CI}-0.07,1.39]\right)$, and the magnitude of the sex difference was weak, $d=0.30$. Both men and women varied widely in their reported attraction: $21 \%$ of men and $23 \%$ of women reported they were "not at all" attracted to their friend, and $62 \%$ of men and $45 \%$ of women reported at least moderate attraction.

In studies 1 and 2, the sex difference in attraction to opposite-sex friends was not statistically significant and was weaker than what has been documented in previous research. One possibility is that each individual study was underpowered due to the sample size. Indeed, when we compiled the two samples, the mean difference was statistically significant, $t(77)=2.47, p=.016\left(M_{\mathrm{d}}=0.62[95 \%\right.$ CI $\left.0.12,1.11]\right)$. However, even compiled across the two samples, our analysis revealed a weaker sex difference $(d=0.28)$ than what has been documented in previous studies using dyads. For example, Bleske-Rechek et al. (2012, study 1) used a similar-sized sample of dyads $(N=88)$ and found a mean sex difference of 1.0 (on a seven-point scale), with an effect size of 0.66 , despite that participants were given instructions that should have led them to select a platonic friend. (In that study, participants were asked to bring in "a friend of the opposite sex who was neither from class nor a family member or romantic partner.") In two other studies, Koenig et al. (2007) asked college students to recruit an opposite-sex friend to participate with them in a study of relationships ( $N_{\mathrm{s}}=119$ pairs and 99 pairs). Although Koenig et al. did not report inferential statistics related to sex differences in attraction, Figs. 1 and 3 of their paper illustrate that the mean sex difference in sexual attraction for both of their samples was greater than 1.0 on their seven-point scale. We tentatively conclude, then, that differences in sample size do not fully explain why the mean difference that we obtained in our samples was weaker than that obtained in other studies.

Another explanation for the weaker sex difference we obtained has to do with our sampling method. In studies 1 and 2, we sampled naturally occurring pairs of friends, which appears to not have been done before in research on oppositesex friends. That is, rather than ask men and women to select a friend to report on or bring to the lab, we went to a high-traffic lounging area where we were likely to find friends spending time together. The "friends" that men and women find themselves with at any given time may not be the same friends who come to mind when they are asked to think of an opposite-sex friend. Indeed, men and women may differ in their mental conceptions of opposite-sex friendship because differences 
in men's and women's mating adaptations might influence how they think about friends. For example, men's stronger orientation toward short-term mating relative to women's (Buss and Schmitt 1993; Schmitt 2005) corresponds with differences in how the sexes select and feel about their oppositesex friends. Men more than women view sexual attraction as a benefit of opposite-sex friendships (Bleske and Buss 2000), and men more than women desire (Bleske-Rechek and Buss 2001) and prioritize (Lewis et al. 2011, 2012) attractiveness in an opposite-sex friend. Men also are more likely than women to report having initiated friendships with a member of the opposite sex because of their feelings of attraction toward them (Salkicevic 2014). It is perhaps not surprising, then, that in studies in which young adults have been asked to either think of an opposite-sex friend or bring an opposite-sex friend to the lab, men report more attraction (Bleske-Rechek et al. 2012) and more sexual and romantic desire toward that person than women do (Bleske-Rechek and Buss 2001; Kaplan and Keys 1997). Thus, in study 3, we tested the hypothesis that men and women have somewhat different types of people in mind when they think of opposite-sex friends.

\section{Study 3}

\section{Method}

\section{Participants}

Through social network sites and course research participation subject pools, we invited young adults at a large Midwestern university to participate in an online study of "Friendship Definitions." We omitted five men who reported a homosexual orientation and 15 women and nine men who did not completely follow the survey instructions (as described below). The final sample included 114 men and 192 women $\left(M_{\text {age }}=19.32, \mathrm{SD}=2.11\right)$. Of those, $38 \%$ were currently involved in a romantic relationship.

\section{Instruments and Procedure}

Previous researchers have used varying degrees of specificity in the instructions they give to men and women when asking about opposite-sex friends. Thus, we prepared two sets of instructions. One ("general") set of instructions read, "Please think of an opposite-sex friend"; the other ("specific") set read, "Please think of an opposite-sex friend who is not a family member or current romantic partner." Each participant was randomly assigned to one of the two sets of instructions and was then asked to type the first name of the friend they thought of so that we could be certain they had a specific person in mind (as noted above, 24 participants who did not follow this instruction were omitted from the dataset). Then, participants were brought to the next screen. It contained one question: "Which of the following describes the person who has come to mind?" Participants could check one or both: "A person of the opposite sex who is a friend" and "A person of the opposite sex who I am physically attracted to." On the final screen, participants reported their sex, current romantic relationship status, age, and sexual orientation.

\section{Results and Discussion}

The results are displayed in Fig. 2. Regardless of instructions given, men's characterizations of the person they had thought of differed from women's (general instructions $\chi^{2}(2$, $n=155)=10.71, p=.005, V=.26$; specific instructions $\chi^{2}(2$, $n=150)=12.21, p=.002, V=.29)$. Men were less likely than women to characterize the person as a friend and more likely than women to characterize the person either as someone they were attracted to or as both a friend and someone they were attracted to. Even among the subset of participants who were currently involved in a romantic relationship and told to think of a friend who was not a family member or current romantic partner, fewer men (79\%) than women (97\%) characterized the person as a friend, and more men (21\%) than women (3\%) characterized the person as both a friend and someone they were attracted to, $\chi^{2}(1, n=61)=5.40, p=.020, V=.30$ (no members of this subset characterized the person only as someone they were attracted to).

\section{General Discussion and Conclusion}

In past studies of opposite-sex friendship, men have reported more physical attraction, sexual attraction, and romantic interest toward their friends than women have (Afifi and Faulkner 2000; Bleske-Rechek and Buss 2001; Bleske-Rechek et al. 2012; Kaplan and Keys 1997). However, when we approached and surveyed male-female friends who were engaged in everyday interactions, both sexes varied widely in their level of attraction toward the friend they were with when approached, and the mean difference was weaker than what has been documented before. We reasoned that in past studies, the sex difference in attraction occurred because men and women had fundamentally different types of people in mind when they thought of an "opposite-sex friend." In study 3, we tested that hypothesis by asking men and women about the person who came to mind when we asked them to think of an opposite-sex friend. We found that men were less likely than women to characterize the person only as a friend, and men were more likely than women to characterize the person as either someone they are attracted to or as both a friend and someone they are attracted to. This pattern implies that men more often mentally define an opposite-sex friend as "a member of the opposite sex to whom I am attracted and would 
Fig. 2 Men's and women's description of the person who of an opposite-sex friend (left columns) or when asked to think of an opposite-sex friend who is not a family member or current romantic partner (right columns) came to mind when asked to think

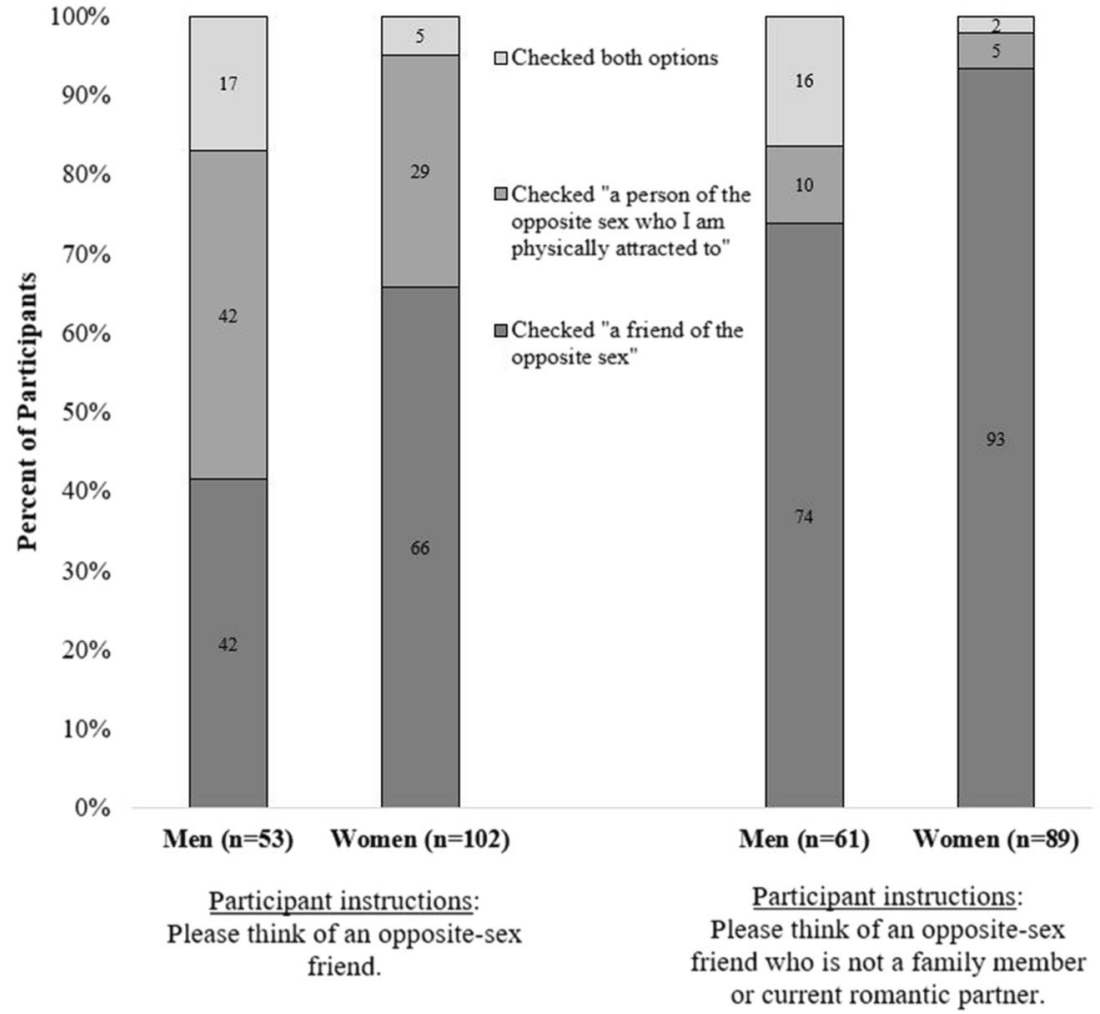

pursue given the opportunity" and women more often mentally define an opposite-sex friend as "a friend of the opposite sex."

Future work needs to address important limitations of the current set of studies. First, in studies 1 and 2, we asked men and women only how physically attracted they were to their friend. We did not ask them how sexually and romantically attracted they were to the friend, and the findings may have been different had we asked those questions. That said, ratings of physical and sexual attraction have been essentially redundant in other studies (Bleske-Rechek et al. 2012), and in Koenig et al. (2007, Figs. 1 and 3), the sex difference in romantic attraction was noticeably smaller than was the sex difference in sexual attraction. Regardless, in future research, we aim to obtain participants' ratings of sexual and romantic attraction as well as physical attraction. Second, the pattern of results from study 3 is consistent with the hypothesis that men and women differ in how they conceptualize opposite-sex friends, but it is also consistent with the possibility that men more strongly value friends who are physically attractive and therefore are more likely than women to think of their more physically attractive friends first (and hence be more attracted to them). We are currently planning a study that might help us address these issues. We plan to use natural sampling to obtain a set of male-female friends. After surveying the dyad members and taking their pictures, we will ask each of them to nominate another opposite-sex friend of theirs to participate in a second phase of the research with them. Each original participant will then come to the lab with their nominated friend (who would also be photographed), and we will survey both members of that dyad as well. With this design, we will be able to compare each participant's attraction toward a friend obtained via natural sampling with their attraction toward a friend obtained via mental conceptions. With subsequent ratings from naïve judges of all participants' attractiveness, we will also be able to compare the physical attractiveness of each participant's friend obtained via natural sampling and each participant's friend obtained via mental conceptions.

Another important limitation is that our samples were relatively homogenous in both age and ethnicity. The vast majority of research on opposite-sex friendship, in general, has utilized college student samples from western societies. Future research with participants of varied ages and ethnic backgrounds will provide useful information on the psychological mechanisms underlying people's mental representations of opposite-sex relationships. It also would be helpful to obtain samples of male-female friendship pairs from the large variety of natural contexts (besides school) in which friends meet and spend time together, such as the workplace, music and sporting events, and community organizations. In future studies, we aim to sample more broadly to determine how the environment from which we sample is related to men's and women's friendship dynamics. With these caveats in mind, we tentatively conclude that young adult men's and women's everyday experiences with opposite-sex friends differ systematically from their mental representations of 
opposite-sex friends. As has been illustrated in other contexts, such as in the study of physical attractiveness (Kniffin and Wilson 2004) and long-term romantic partnerships (Driver and Gottman 2004), a deeper understanding of opposite-sex friendship dynamics might be garnered from studying them under naturalistic conditions.

Acknowledgments This research was funded by the Office of Research and Sponsored Programs at the University of Wisconsin-Eau Claire.

\section{Compliance with Ethical Standards}

Conflict of Interest The authors declare that they have no conflict of interest.

\section{References}

Afifi, W. A., \& Faulkner, S. L. (2000). On being 'just friends': the frequency and impact of sexual activity in cross-sex friendships. Journal of Social and Personal Relationships, 17, 205-222.

Baumgarte, R., \& Nelson, D. (2009). Preference for same- versus crosssex friendships. Journal of Applied Social Psychology, 39, 901-917.

Bleske, A. L., \& Buss, D. M. (2000). Can men and women be just friends? Personal Relationships, 7, 131-151.

Bleske-Rechek, A. L., \& Buss, D. M. (2001). Opposite-sex friendships: sex differences and similarities in initiation, selection, and dissolution. Personality and Social Psychology Bulletin, 27, 1310-1323.

Bleske-Rechek, A., Somers, E., Micke, C., Erickson, L., Matteson, L., Schumacher, B., Stocco, C., \& Ritchie, L. (2012). Benefit or burden? Attraction in cross-sex friendship. Journal of Social and Personal Relationships, 29, 569-596.

Buss, D. M. (1989). Sex differences in human mate preferences: evolutionary hypotheses tested in 37 cultures. Behavioral and Brain Sciences, 12, 1-49.

Buss, D. M., \& Schmitt, D. P. (1993). Sexual strategies theory: an evolutionary perspective on human mating. Psychological Review, 100, 204-232.

Driver, J. L., \& Gottman, J. M. (2004). Daily marital interactions and positive affect during marital conflict among newlywed couples.
Family Process, 43, 301-314. doi:10.1111/j.1545-5300.2004. 00024.x.

Hunt, L. L., Eastwick, P. W., \& Finkel, E. J. (2015). Leveling the playing field: longer acquaintance predicts reduced assortative mating on attractiveness. Psychological Science, 26, 1046-1053. doi:10. 1177/0956797615579273.

Kaplan, D. L., \& Keys, C. B. (1997). Sex and relationship variables as predictors of sexual attraction in cross-sex platonic friendships between young heterosexual adults. Journal of Social and Personal Relationships, 14, 191-206.

Kniffin, K. M., \& Wilson, D. S. (2004). The effect of nonphysical traits on the perception of physical attractiveness: three naturalistic studies. Evolution and Human Behavior, 25, 88-101.

Koenig, B. L., Kirkpatrick, L. A., \& Ketelaar, T. (2007). Misperception of sexual and romantic interests in opposite-sex friendships: four hypotheses. Personal Relationships, 14, 411-429.

Lewis, D. M. G., Conroy-Beam, D., Al-Shawaf, L., Raja, A., DeKay, W., \& Buss, D. M. (2011). Friends with benefits: the evolved psychology of same- and opposite-sex friendship. Evolutionary Psychology, 9, 543-563.

Lewis, D. M. G., Al-Shawaf, L., Conroy-Beam, D., Asao, K., \& Buss, D. M. (2012). Friends with benefits II: mating activation in oppositesex friendships as a function of sociosexual orientation and relationship status. Personality and Individual Differences, 53, 622-628.

Monsour, M. (2002). Women and men as friends: relationships across the life span in the 21st century. Mahwah, NJ: Lawrence Erlbaum.

O'Meara, J. D. (1989). Cross-sex friendships: four basic challenges of an ignored relationship. Sex Roles, 21, 525-543.

Reeder, H. M. (2000). 'I like you ... as a friend': the role of attraction in cross-sex friendships. Journal of Social and Personal Relationships, 17, 329-348.

Salkicevic, S. (2014). Some determinants of opposite-sex friendship initiation and dissolution. Review of Psychology, 21, 31-39.

Schmitt, D. P. (2005). Sociosexuality from Argentina to Zimbabwe: a 48nation study of sex, culture, and strategies of human mating. Behavioral and Brain Sciences, 28, 247-311.

Schoonover, K., \& McEwan, B. (2014). Are you really just friends? Predicting the audience challenge in cross-sex friendships. Personal Relationships, 21, 387-403.

Swain, S. (1992). Men's friendships with women: intimacy, sexual boundaries, and the informant role. In P. Nardi (Ed.), Men's friendships (pp. 153-171). Thousand Oaks: Sage.

Werking, K. (1997). We're just good friends: men and women in nonromantic relationships. New York: The Guilford Press. 